\title{
The Effect of Calcipotriol on the Expression of Human $\beta$ Defensin-2 and LL-37 in Cultured Human Keratinocytes
}

\author{
Beom Joon Kim, ${ }^{1}$ Yong Kwan Rho, ${ }^{1}$ Hye In Lee, ${ }^{1}$ Mi Sook Jeong, ${ }^{2}$ Kapsok Li, ${ }^{1}$ Seong Jun Seo, ${ }^{1}$ \\ Myeung Nam Kim, ${ }^{1}$ and Chang Kwun Hong ${ }^{1}$
}

${ }^{1}$ Department of Dermatology, Chung-Ang Medical Research Center, College of Medicine, Chung-Ang University,
Seoul 156-755, South Korea
${ }^{2}$ Chung-Ang Medical Research Center, College of Medicine, Chung-Ang University, Seoul 156-755, South Korea

Correspondence should be addressed to Seong Jun Seo, drseo@hanafos.com

Received 16 August 2009; Accepted 5 December 2009

Recommended by Yasunobu Yoshikai

Background. Vitamin D has been reported to regulate innate immunity by controlling the expression of antimicrobial peptides (AMPs). Objective. We investigated the effect of calcipotriol on the expression of AMPs in human cultured keratinocytes. Methods. Keratinocytes were treated with lipopolysaccharide (LPS), TNF- $\alpha$, Calcipotriol and irradiated with UVB, cultured, and harvested. To assess the expression of human beta defensin-2 and LL-37 in the control group, not exposed to any stimulants, the experimental group was treated with LPS, TNF- $\alpha$, or UVB, and another group was treated again with calcipotriol; reverse transcriptasepolymerase chain reaction, Western blotting, and immunohistochemical staining were performed. Results. In the experimental group treated with LPS, UVB irradiation, and TNF- $\alpha$, the expression of $\beta$-defensin and LL-37 was increased more than in the control group and then decreased in the experimental group treated with calcipotriol. Conclusions. Calcipotriol suppressed HBD2 and LL-37, which were stimulated by UVB, LPS, and TNF- $\alpha$.

Copyright () 2009 Beom Joon Kim et al. This is an open access article distributed under the Creative Commons Attribution License, which permits unrestricted use, distribution, and reproduction in any medium, provided the original work is properly cited.

\section{Introduction}

Antimicrobial peptides (AMPs) are small molecular weight proteins with a broad spectrum of antimicrobial activity against bacteria, viruses, and fungi $[1,2]$. They are involved in the first line of defense as well as coordination of the innate and adaptive immune system [3]. In addition, recent studies have shown that AMPs can function as chemokines, proteinases, and neuropeptides [4]. Many AMPs have been found in a variety of tissues such as respiratory, urogenital, and skin epithelium [5-7]. Human ß-defensin (HBD) and cathelicidin have been identified as the principal peptides in the skin.

These AMPs exhibit an imbalance or dysregulation in some inflammatory skin diseases such as atopic dermatitis and psoriasis. LL-37 as a peptide form of human cathelicidin and HBD-2 both have been reported to be downregulated in the skin of patients with atopic dermatitis compared to patients with psoriasis [6]. Unlike atopic dermatitis, HBD and cathelicidin are strongly increased in keratinocytes in psoriatic plaques [8]. Considering these findings, AMPs have been thought to play a role in the pathogenesis of inflammatory skin diseases.

The mechanisms underlying the regulation of AMP expression remain poorly understood. Many cytokines, Tolllike receptors (TLRs), and vitamin D are thought to be involved in the regulation of AMP expression. The activation of Toll-like receptors has been reported to lead to the nuclear factor kappa $\mathrm{B}(\mathrm{NF} \kappa \mathrm{B})$ dependent induction of a variety of AMPs including the defensins [9-11]. HBD-2 and -3 have been reported to be induced by interleukin (IL)- $1 \alpha$, IL- $\beta$, and the tumor necrosis factor (TNF)- $\alpha[10,12]$.

Recently, vitamin D has been reported to be important in cutaneous immune modulation as well as calcium regulation and bone metabolism. Vitamin D induces epidermal keratinocytes to growth arrest, differentiation, and changes 
in cytokine expression [13]. In addition, vitamin D has been associated with an increase in the expression of LL-37 in cultured human keratinocytes and in human skin in vivo [14]. Moreover, the vitamin D response element has been identified in the cathelicidin promoter [15]. Vitamin Dinduced cathelicidin worsens the inflammation associated with psoriasis; however, vitamin $\mathrm{D}$ has been used for the treatment of psoriasis. The molecular effects of vitamin D on the AMPs have not been elucidated in patients with psoriasis.

In this study, we investigated the effects of calcipotriol, a vitamin $\mathrm{D}_{3}$ analogue on the expression of AMPs in human cultured keratinocytes. The results showed that calcipotriol suppressed the upregulated expression of hBD-2 and LL-37, stimulated by ultraviolet B (UVB), lipopolysaccharide (LPS), and TNF- $\alpha$.

\section{Materials and Methods}

2.1. Cell Culture. The keratinocytes were cultured in Keratinocyte Basal Medium (Cambrex, Walkersville, MD., USA), supplemented with KGM SingleQuots (Cambrex, Walkersville, MD., USA) grown in a $75 \mathrm{~cm}^{2}$ flask and incubated with $5 \% \mathrm{CO} 2$ at $37^{\circ} \mathrm{C}$. The cultured keratinocytes were divided in the amount of $2 \times 10^{5} / \mathrm{mL}$ and plated in a standard flat bottomed $10 \mathrm{~cm}^{2}$ polystyrene plate. The cells were starved overnight in KBM supplemented with free KGM. Some cells were then irradiated with $20 \mathrm{~mJ} / \mathrm{cm}^{2}$ of UVB and treated with LPS (Sigma, St. Louis, MO., USA) $5 \mu \mathrm{g} / \mathrm{mL}$, TNF- $\alpha$ (Sigma, St. Louis, MO., USA) $100 \mathrm{U} / \mathrm{mL}$, and Calcipotriol (Sigma, St. Louis, MO., USA) $10^{-9} \mu \mathrm{g}$ and incubated for 6, 12, and 24 hours.

2.2. Ultraviolet B Irradiation (UVB). The dose of irradiation used was $20 \mathrm{~mJ} / \mathrm{cm}^{2}$; this dose was chosen based on preliminary data. UVB irradiation was delivered with a Philips TL 20W/12 (Eindhoven, The Netherlands), a fluorescent bulb emitting 280-320 nm wavelength with a peak at $313 \mathrm{~nm}$. Before UVB irradiation, the medium was removed and covered with phosphate buffered saline (PBS). Irradiation output was monitored with a Waldmann UVmeter (Waldmann, Villigen-Schwenningen, Germany).

2.3. Preparation of Primers. We synthesized the PCR primers based on Gene Bank data. The primers were chemically synthesized using a DNA synthesizer (Pharmacia, Björkgatan, Uppsala, Sweden). The sequences were as follows:

$h B D-2(128 b p)$ :

$5^{\prime}$-ATCTCCTCTTCTCGTTCCTC-3' (sense), $5^{\prime}$-ACCTTCTAGGGCAAAAGACT-3 (anti-sense).

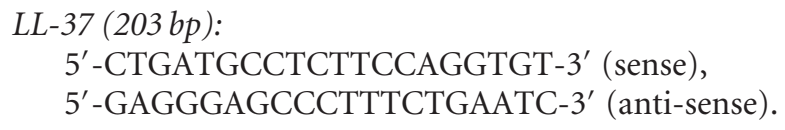

GAPDH (593 bp):

5' -CCACCCATGGCAAATTCCATGGCA-3' (sense), 5'-GGTGCTGCTTGTTAGGAGGTCAAGTAAAGGGC-3' (anti-sense).
2.4. Reverse Transcription-Polymerase Chain Reaction (RT$P C R)$. Total RNA was isolated from the cultured keratinocytes using TRIzol reagent (Invitrogen, Carlsbad, CA, USA). To the cells, $1 \mathrm{~mL}$ of TRIzol reagent was added in a culture dish. After 5 minutes at room temperature, $0.2 \mathrm{~mL}$ of chloroform was added per $1 \mathrm{~mL}$ of TRIzol reagent; the tubes were shaken vigorously by hand for 15 seconds and then they were incubated at $15^{\circ} \mathrm{C}$ to $30^{\circ} \mathrm{C}$ for 3 minutes. The mixtures were centrifuged at $12,000 \mathrm{rpm}$ at $4^{\circ} \mathrm{C}$ for 15 minutes, the upper aqueous phase was transferred to a fresh tube, and the same volume of 2-propanol was added. After the incubation at $4^{\circ} \mathrm{C}$ for 15 minutes, the specimen was centrifuged at $12,000 \mathrm{rpm}$ at $4^{\circ} \mathrm{C}$ for 15 minutes. The supernatant was removed, then washed with $500 \mu \mathrm{l}$ of $70 \%$ ethanol, and centrifuged at $12,000 \mathrm{rpm}$ at $4^{\circ} \mathrm{C}$ for 5 minutes; the RNA pellet was then briefly dried. The purified RNA was dissolved in diethyl pyrocarbonate- distilled water (DEPC-DW) $30 \mu \mathrm{l}$. Next, $3 \mu \mathrm{g}$ of total cellular RNA was reverse transcripted at $42^{\circ} \mathrm{C}$ for 30 minutes in $20 \mu \mathrm{l}$ volume containing $1 \mu \mathrm{l}$ reverse transcriptase (TaKaRa, Shiga, Japan), 10X buffer $2 \mu \mathrm{l}, 10 \mathrm{mM}$ dNTP $2 \mu \mathrm{l}$ (dNTP mix), oligo dT primer $1 \mu \mathrm{l}$, RNase inhibitor $0.5 \mu \mathrm{l}$, and $25 \mathrm{mM} \mathrm{MgCl} 24 \mu \mathrm{l}$.

Then, $2 \mu \mathrm{l}$ of each cDNA sample from the RT-PCR was amplified by PCR in $25 \mu \mathrm{l}$ containing 10X buffer $2.5 \mu \mathrm{l}$, $25 \mathrm{mM} \mathrm{MgCl} 22.5 \mu \mathrm{l}$, and $10 \mathrm{pmol} 0.75 \mu \mathrm{l}$ primer.

The thermal cycle profiles were as follows: $94^{\circ} \mathrm{C}$ for 5 minutes, 35 cycles at $94^{\circ} \mathrm{C}$ for 1 minute, $59^{\circ} \mathrm{C}$ for 1 minute, $72^{\circ} \mathrm{C}$ for 1 minute, and a final extension step at $72^{\circ} \mathrm{C}$ for 10 minutes.

2.5. Electrophoresis. The products were run on $1.5 \%$ agarose gel containing $1 \mu \mathrm{g}$ of ethidium bromide per millimeter; $20 \mu \mathrm{l}$ of reaction mixture was mixed with loading buffer separated by electrophoresis for 15 minutes at 100 voltage and visualized by UV transillumination.

2.6. Quantitative Analysis. Densitometry was performed on the hybrids of the PCR products of hBD-2, LL-37 and GAPDH, and the DIG on chemiluminescent film was calculated (volume of hBD-2/volume of GAPDH X100, volume of LL-37 /volume of GAPDH X100).

2.7. Statistical Analysis. The amount of hBD-2 and LL-37 in the keratinocytes between the control and stimulated groups was statistically compared using the ANOVA.

2.8. Western Blotting. The cultured keratinocytes were lysed in a buffer containing $50 \mathrm{mM}$ Tris- $\mathrm{Cl}(\mathrm{pH} 8.0), 150 \mathrm{mM}$ $\mathrm{NaCl}, 0.02 \%$ sodium azide, $100 \mu \mathrm{g} / \mathrm{mL}$ phenylmethanesulfonyl fluoride (PMSF), $1 \mu \mathrm{g} / \mathrm{mL}$ aprotinin, and $1 \%$ Triton $\mathrm{X} 100$, and then centrifuged at $12,000 \mathrm{rpm}$ at $4^{\circ} \mathrm{C}$ for 30 minutes. The supernatant was transferred to a new tube. Then, $30 \mu \mathrm{g}$ of soluble protein was loaded onto a $15 \%$ sodium dodecyl sulfate polyacrylamide gel for electrophoresis (SDSPAGE) with a sample buffer containing $1 \mathrm{M}$ Tris and glycerol $50 \%$; the samples were heated at $95^{\circ} \mathrm{C}$ for 5 minutes prior to loading the gel. 


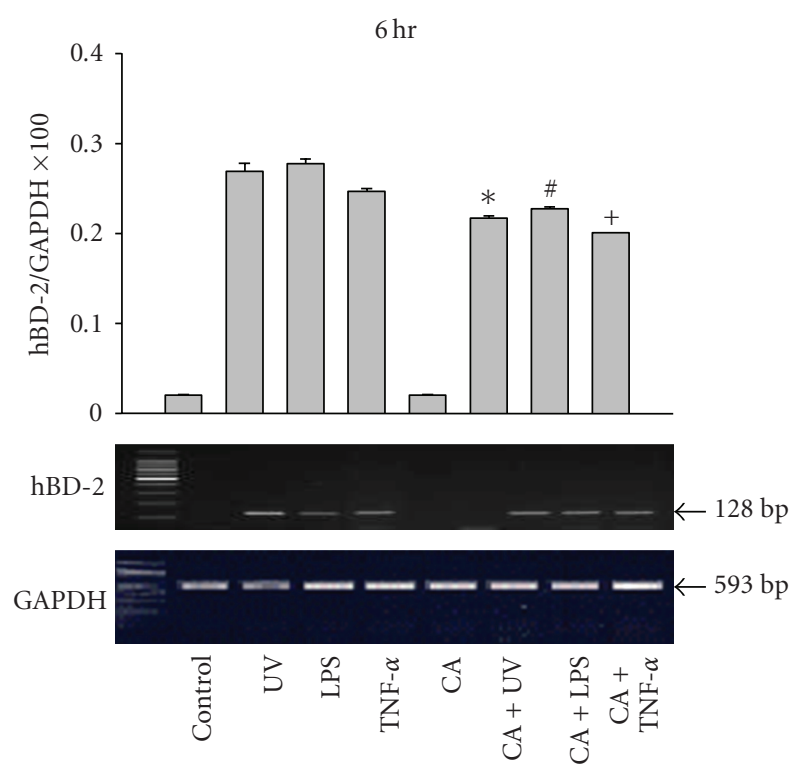

(a)

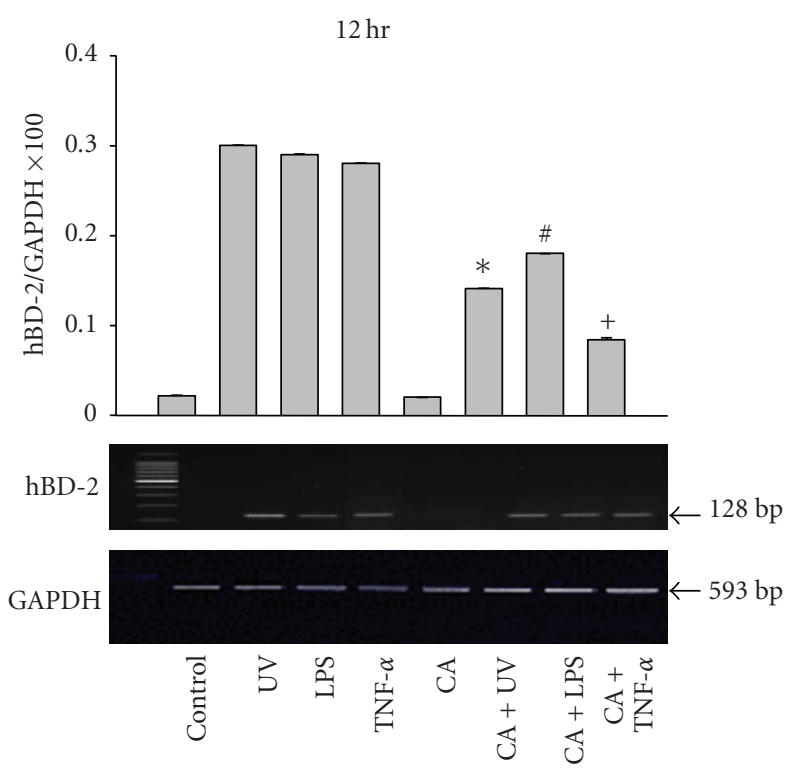

(b)

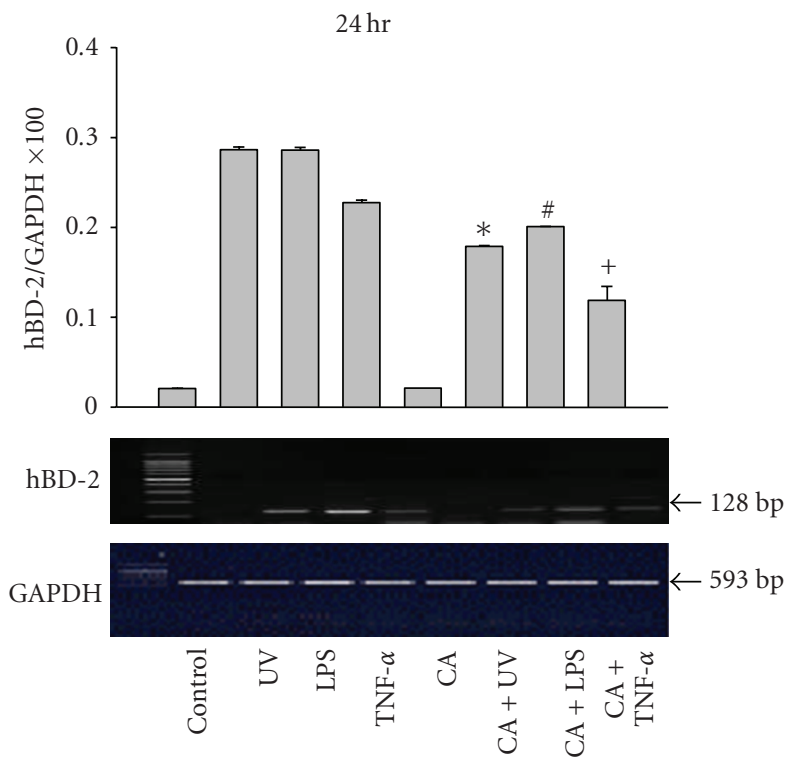

(c)

FIgURE 1: The expression of hBD-2 mRNA in keratinocytes was upregulated when stimulated with LPS, TNF- $\alpha$, and UVB irradiation at 6, 12 , and 24 hours. The hBD-2 mRNA expression was decreased after treatment with calcipotriol (CA). $*$ : Statistically significant between UV and CA + UV $(P<.01)$. \#: Statistically significant between LPS and CA + LPS $(P<.01)$. +: Statistically significant between TNF-s and CA + TNF-a $(P<0.01)$.

For detection of LL-37 and hBD-2, the separated proteins, from the gel electrophoresis, were transferred onto a nitocellulose membrane (Osmonics, Milwaukee, WI, USA) at $0.16 \mathrm{~A}$ for 1 hour. The membrane was washed three times with Tris-buffered saline tween 20 (TBST) and blocked with $5 \%$ skim milk for 1 hour at room temperature. Following this, the membrane was incubated overnight at $4^{\circ} \mathrm{C}$ with goat antihuman hBD-2 polyclonal antibodies $(1: 1000$ in $5 \%$ bovine serum albumin, SantaCruz, Delaware, CA, USA) or goat antihuman LL-37 polyclonal antibodies $(1: 1000$ in 5\% bovine serum albumin, SantaCruz, Delaware, CA, USA) and then washed three times with TBST. Then, the secondary mouse anti-goat peroxidase conjugated antibodies $(1: 2000$ in blocking solution, SantaCruz, Delaware, CA, USA) were incubated for 1 hour at room temperature.

After washing the membrane with TBST, the membrane was developed with electrochemiluminescence (ECL) solution (SantaCruz, Delaware, CA, USA) for 3 minutes then exposed to X-ray film (Roche, Indianapolis, IN, USA). 

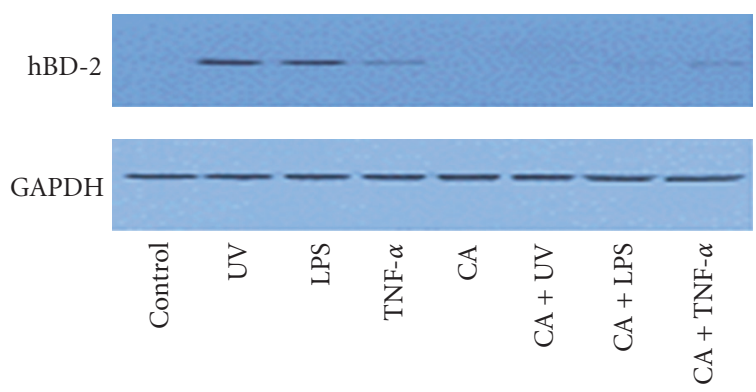

FIgURE 2: Expression of hBD protein in keratinocytes were evaluated by Western blotting using polyclonal antibody to hBD at 6,12 , and 24 hours post stimulation. The expression of hBD was decreased after additional treatment with calcipotriol compared to stimulation with LPS, TNF- $\alpha$, and UVB irradiation in the keratinocytes.

2.9. Immunohistochemistry (IHC) for hBD-2. The keratinocytes were cultured on a coverslip (Nunc, Rochester, NY, USA). The cells were fixed for 10 minutes in $4 \%$ paraformaldehyde and washed three times for 5 minutes with PBS. Endogenous peroxidase was inactivated by incubation with $3 \%$ hydrogen peroxide at room temperature for 5 minutes and blocked with 3\% BSA for 20 minutes followed by washing. The cells were incubated overnight at $4^{\circ} \mathrm{C}$ with goat anti-hBD-2 polyclonal antibodies, diluted $1: 100$ in PBS, then rinsed three times with PBS, and incubated with donkey antigoat peroxidase-conjugated antibodies (1:200 in PBS) for 1 hour at room temperature. After washing three times, the cells were immersed in 3,3'-diaminobenzidine (DAKO, Glostrup, Denmark) and then rinsed with distilled water.

2.10. Immunohistochemistry (IHC) for LL-37. The keratinocytes were cultured on a coverslip (Nunc, Rochester, NY, USA). The cells were fixed for 10 minutes in $4 \%$ paraformaldehyde and washed three times for 5 minutes with PBS. Endogenous peroxidase was inactivated by incubation with $3 \%$ hydrogen peroxide at room temperature for 5 minutes and blocked with 3\% BSA for 20 minutes, followed by washing. The cells were incubated overnight at $4^{\circ} \mathrm{C}$ with goat anti-LL-37 polyclonal antibodies, diluted $1: 100$ in PBS, rinsed three times with PBS, and incubated with donkey antigoat peroxidase-conjugated antibodies ( $1: 200$ in PBS) for 1 hour at room temperature. After washing three times, the cells were immersed in 3,3'-diaminobenzidine (DAKO, Glostrup, Denmark) and rinsed with distilled water.

\section{Results}

\subsection{Results for $h B D$}

3.1.1. RT-PCR. hBD-2 mRNA expression was not detected in the cultured keratinocytes of the unstimulated controls. The HBD-2 mRNA expression was upregulated in the UVB-irradiated, LPS, and TNF- $\alpha$-stimulated groups. The stimulant-induced upregulation of HBD-2 mRNA expression was decreased after treatment with calcipotriol
(Figure 1). These results were statistically significant when compared to the results of the control group $(P<.001)$.

3.1.2. Western Blotting. hBD-2 protein expression was assessed by Western blotting using polyclonal antibodies against hBD-2 at 6,12 , and 24 hours after stimulation. The levels of hBD-2 protein expression in the UVB-irradiated, LPS, and TNF- $\alpha$-treated group were more intense than in the unstimulated control group. The expression of $\mathrm{hBD}$ decreased after additional treatment with calcipotriol compared to the stimulated group, with LPS, TNF- $\alpha$, and UVB irradiation in the keratinocytes (Figure 2).

3.1.3. Immunohistochemistry (IHC). hBD-2 protein expression in the keratinocytes was quantified via IHC analysis. The UVB-irradiated, LPS, and TNF- $\alpha$-stimulated groups stained more strongly for hBD-2 protein expression than did the unstimulated groups. In the additional groups treated with calcipotriol, there was a less intense response than with exposure to the stimulants (Figure 3 ).

\subsection{Results of $L L-37$}

3.2.1. RT-PCR. The expression of LL-37 mRNA in keratinocytes was also upregulated when stimulated with LPS, TNF- $\alpha$, and UVB irradiation at 6,12 , and 24 hours. Similar to the results of $\mathrm{hBD}-2, \mathrm{LL}-37$ mRNA expression was decreased after treatment with calcipotriol (Figure 4). These results were statistically significant when compared to the results of the control group $(P<.001)$.

3.2.2. Western Blotting. LL-37 protein expression was assessed via Western blotting using polyclonal antibodies against hBD-2 at 6,12 , and 24 hours after stimulation. The level of LL-37 protein expression in the UVB-irradiated, LPS, and TNF- $\alpha$-treated groups was more intense than observed in the unstimulated control group. The expression of LL37 decreased after additional treatment with calcipotriol compared to the keratinocytes stimulated with LPS, TNF- $\alpha$, and UVB irradiation (Figure 5).

3.2.3. Immunohistochemistry (IHC). LL-37 protein expression in the cultured keratinocytes was quantified by IHC analysis. The UVB-irradiated, LPS and TNF- $\alpha$-stimulated groups stained more strongly for LL-37 protein expression than did the unstimulated groups. In the additional groups treated with calcipotriol the results were less intense than when exposed to the stimulants (Figure 6).

\section{Discussion}

AMPs were first found to act as endogenous antibiotics involved in destroying microbes. Currently, they are thought to play an important role in triggering and coordinating innate and adaptive immunity. Among the more than 20 AMPs, the cathelicidins and defensins are the best characterized in the skin. Defensins, as cationic peptides, contain 6 to 8 cysteine residues that form characteristic disulfide 
IHC

Defensin-2

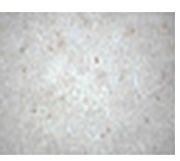

Control

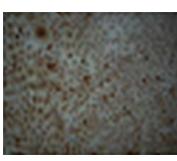

UV

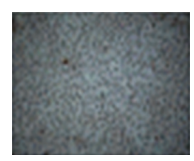

LPS

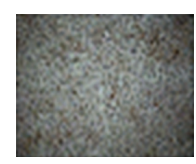

TNF- $\alpha$

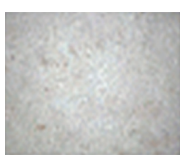

$\mathrm{CA}$

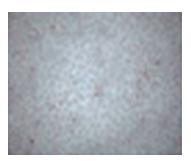

$\mathrm{CA}+\mathrm{UV}$

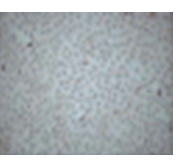

CA + LPS

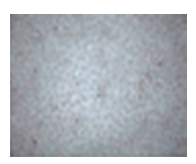

$\mathrm{CA}+\mathrm{TNF}-\alpha$

FIGURE 3: Immunostaining for hBD was more intense on LPS, TNF- $\alpha$ treated, and UV irradiated groups than in the normal control. In the additional groups treated with calcipotriol for $\mathrm{hBD}$, the results were less intense than the stimulant groups.

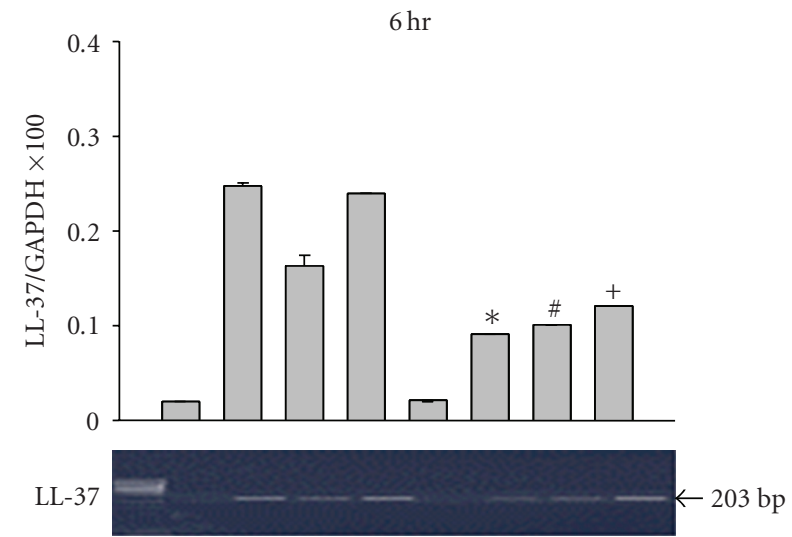

GAPDH

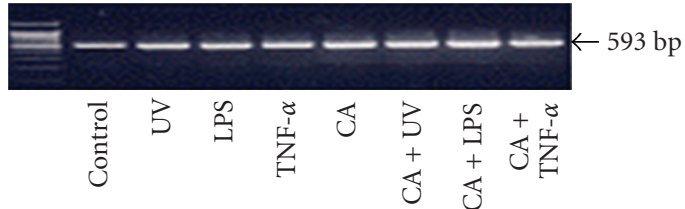

(a)

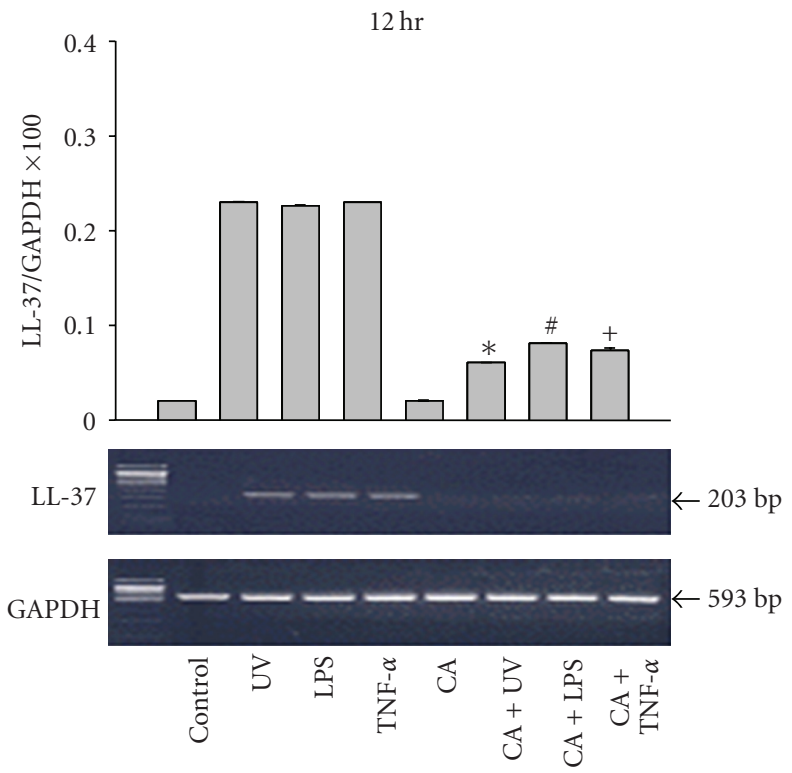

(b)

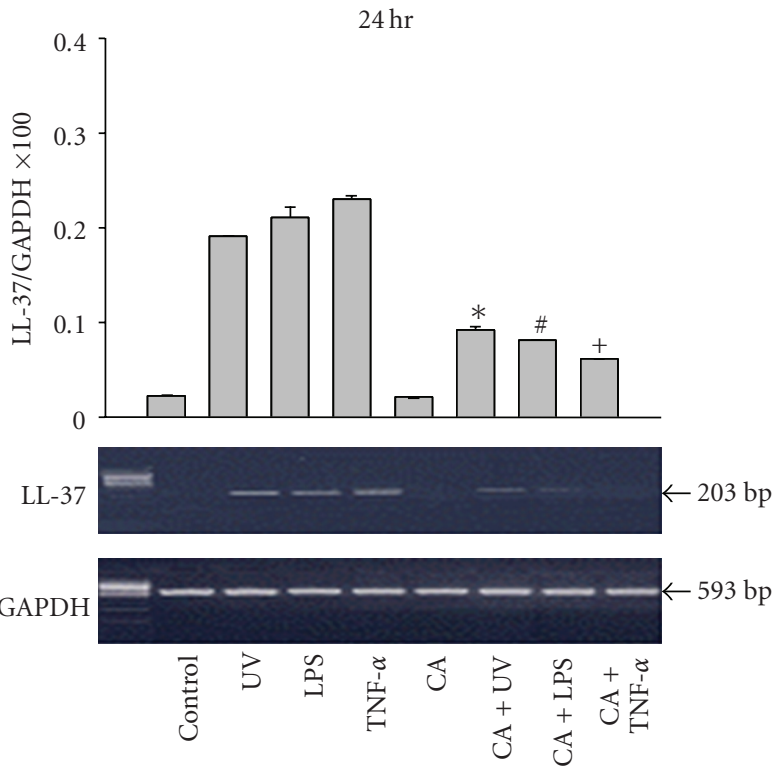

(c)

FIGURE 4: The expression of LL-37 mRNA in the keratinocytes was also upregulated when stimulated with LPS, TNF- $\alpha$, and UVB irradiation at 6,12 , and 24 hours. Similar to the hBD-2 results, LL-37 mRNA expression decreased after treatment with calcipotriol. $*$ : Statistically significant between UV and CA + UV $(P<.01)$. \#: Statistically significant between LPS and CA + LPS $(P<.01)$. + : Statistically significant between TNF-s and CA + TNF-a $(P<.01)$. 


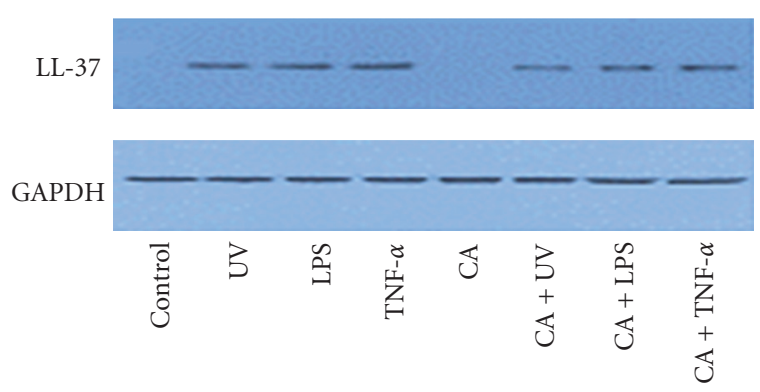

Figure 5: The expression of LL-37 protein in keratinocytes was evaluated by Western blotting using polyclonal antibody to LL-37 at 6,12 , and 24 hours post stimulation. The expression of LL37 was downregulated after additional treatment with calcipotriol compared to the stimulated keratinocytes with LPS, TNF- $\alpha$, and UVB irradiation.

bridges [16]. Among alpha, beta, and theta defensins, HBDs 1 to 4 are expressed in keratinocytes. HBDs 2 to 4 can be induced by calcium and phorbol 12 myristate 13 acetate (PMA) and can be inhibited by retinoic acid [17]. Cathelicidins are an important AMP family in the skin, and the precursor protein, human cationic antimicrobial peptide $18 \mathrm{kDa}$ (hCAP 18), is processed to LL-37 [18]. In human keratinocytes, cathelicidins are induced by infections, interleukin-6, and wounds [19, 20].

The expression and function of the AMPs are important for the appropriate modulation of immunity. In the case of atopic dermatitis, the expressions of both HBD-2 and LL-37 are significantly decreased in skin lesions [6]. These distinct defects of immune defense account for the increased incidence of skin infections with this disorder. The reduction of AMP expression is thought to be caused by the inhibitory effects of IL- 4 and IL-13 on TNF- $\alpha$ and interferon (IFN)- $\gamma$ stimulation in keratinocytes [21].

The mechanisms of AMP regulation in keratinocytes are incompletely understood. The expression of the AMPs is affected by various factors such as UVB, infections, inflammatory cytokines, and vitamin D. Cathelicidin is induced by vitamin $\mathrm{D}$ when TLR-2 and the cytokine transforming growth factor- $\beta$ are activated after a skin injury [20]. Lowdose UVB has been reported to upregulate the AMPs and a permeability barrier functions via vitamin $\mathrm{D}$ [22]. TNF- $\alpha$ induces the expression of HBD-2 and $3[9,12]$. The results of this study confirmed prior findings that UVB, LPS, and TNF- $\alpha$ increased the expression of HBD-2 and LL- 37 .

Vitamin D is an important regulator of cutaneous immunity in addition to its role in calcium homeostasis and bone metabolism. It has been reported to regulate innate immunity and enable efficient antimicrobial defenses. Several research groups confirmed that cathelicidin expression is regulated through the vitamin D3 pathway and cathelicidin is a direct target of vitamin D3 in keratinocytes $[14,15]$. In keratinocytes, human cathelicidin is directly regulated by 1,25-dihydroxyvitamin D3 (1,25D3) through a vitamin D3 responsive element (VDRE) in the human cathelicidin gene CAMP [23]. Additional elements of the vitamin D3 signalling cascade have been identified that lead to increased cathelicidin such as recruitment of coactivators or epigenetic changes such as histone acetylation [24]. This inducing effect of vitamin D analogs on cathelicidin expression was confirmed in cell culture experiments using primary keratinocytes: Vitamin D analogs such as calcipotriol induced cathelicidin through activation of the VDR and subsequent CAMP transcription.

Several studies have shown that AMPs are also involved in inflammatory skin diseases such as rosacea and psoriasis [25, 26]. Recent publications highlight the role of dysregulated expression of AMPs in the pathogenesis of psoriasis. HBD2 and cathelicidin are strongly increased in keratinocytes in psoriatic plaques6. In a recent study, cathelicidin LL-37 isolated from lesional skin was shown to form complexes with human self-DNA to activate plasmocytoid dendritic cells (pDCs) [8]. These pDCs released IFN- $\alpha$ to activate the $\mathrm{T}$ cell response leading to cutaneous inflammation. In addition, cathelicidin has been shown to induce the expression of proinflammatory cytokines in keratinocytes, angiogenesis, chemotaxis of immune cells, and wound repair [27-29].

Strategies to decrease cathelicidin in keratinocyte by targeting vitamin D3 metabolism and signaling might be beneficial in psoriasis. However, paradoxically for a long time vitamin D3 analogs have been used in the therapy of psoriasis. As vitamin D3 analogs activate the vitamin $D$ receptor, we would expect that they induce cathelicidin presumably aggravating inflammation in psoriasis. Still, the opposite is true: vitamin $\mathrm{D}$ analogs are a mainstay in the topical treatment of psoriasis. They ameliorate cutaneous inflammation and reverse morphological changes within lesional skin [30]. To date mechanisms that could explain this paradoxical effect of vitamin $\mathrm{D}$ analogue for psoriasis have not been completely examined yet.

This study demonstrated that previously increased AMPs like psoriatic skin lesions could be suppressed by calcipotriol. As seen in this study with RT-PCR, Western blotting, and immunohistochemical staining, upregulated HBD-2 and LL37 were suppressed after treatment with calcipotriol, a vitamin $\mathrm{D}$ analogue. Although its inhibitory action was not time-dependent, calcipotriol decreased the expression of the AMPs stimulated by UVB, LPS, and TNF- $\alpha$. Therefore, vitamin $\mathrm{D}$ appears to downregulate increased HBD-2 and LL-37 in stimulated keratinocytes. Thus, we speculate that vitamin D might induce AMPs under noninflammatory conditions, on the contrary downregulate previously induced AMPs under inflammatory conditions like psoriatic skin. Recent published study analyzed the expression of HBD and cathelicidin in psoriatic plaques before and after treatment with the vitamin D analogue calcipotriol [31]. Keratinocytes in lesional psoriatic plaques showed decreased expression of the AMPs HBD2 and HBD3 after topical treatment with calcipotriol. In contrast, cathelicidin antimicrobial peptide expression was increased by calcipotriol. Also, vitamin $\mathrm{D}$ analogs induced cathelicidin through activation of the vitamin D receptor and MEK/ERK signaling and blocked IL17A induced HBD2 expression in cultured human epidermal keratinocyte. These studies suggest that vitamin D analogs differentially alter AMP expression in lesional psoriatic 
IHC

LL-37

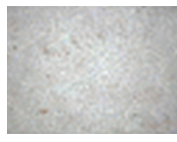

Control

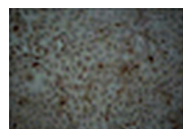

UV

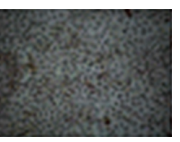

LPS

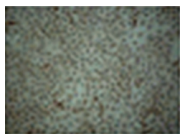

TNF- $\alpha$

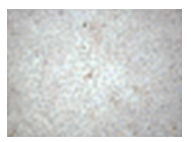

CA

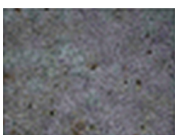

$\mathrm{CA}+\mathrm{UV}$

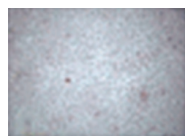

CA + LPS

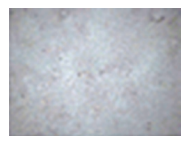

$\mathrm{CA}+\mathrm{TNF}-\alpha$

FIgURE 6: Immunostaining of LL-37 was more intense in the LPS, TNF- $\alpha$ treated, and UV irradiated groups than in the normal control. In the additional groups treated with calcipotriol, immunostaining for LL-37 was less intense than for the stimulant groups.

skin and cultured keratinocytes. Although our esperimental results are contrary to current understanding of vitamin D effect on AMP, these results also might present possibility for another pathway of vitamin $\mathrm{D}$ analogs in psoriasis patients. Vitamin D signaling pathway is very complex and consists of various elements. Further study that could make clear the mechanism for explaining downregulating effect of vitamin $\mathrm{D}$ on the induced AMP expression is processing now. Future experimental work on the molecular pathways and clinical correlations are needed to understand AMP and vitamin D.

In conclusion, calcipotriol suppressed induced HBD-2 and LL-37, stimulated by UVB, LPS, and TNF- $\alpha$. These findings suggest that vitamin $\mathrm{D}$ modulates the expressions of AMPs in chronic skin diseases with highly expressed AMPs.

\section{Acknowledgment}

This study was supported by a grant of the Korea Healthcare technology R\&D Project, Ministry for Health, Welfare \& Family Affairs, South Korea (A091121).

\section{References}

[1] C. Fulton, G. M. Anderson, M. Zasloff, R. Bull, and A. G. Quinn, "Expression of natural peptide antibiotics in human skin,” The Lancet, vol. 350, no. 9093, pp. 1750-1751, 1997.

[2] J. Harder, J. Bartels, E. Christophers, and J.-M. Schroder, "A peptide antibiotic from human skin," Nature, vol. 387, no. 6636, p. 861, 1997.

[3] J. Schauber and R. L. Gallo, "Expanding the roles of antimicrobial peptides in skin: alarming and arming keratinocytes," Journal of Investigative Dermatology, vol. 127, no. 3, pp. 510512, 2007.

[4] D. Yang, O. Chertov, and J. J. Oppenheim, "Participation of mammalian defensins and cathelicidins in anti-microbial immunity: receptors and activities of human defensins and cathelicidin (LL-37)," Journal of Leukocyte Biology, vol. 69, no. 5, pp. 691-697, 2001.

[5] C. Fulton, G. M. Anderson, M. Zasloff, R. Bull, and A. G. Quinn, "Expression of natural peptide antibiotics in human skin," The Lancet, vol. 350, no. 9093, pp. 1750-1751, 1997.

[6] P. Y. Ong, T. Ohtake, C. Brandt, et al., "Endogenous antimicrobial peptides and skin infections in atopic dermatitis," The New England Journal of Medicine, vol. 347, no. 15, pp. 11511160, 2002.

[7] J. Schauber and R. L. Gallo, "Antimicrobial peptides and the skin immune defense system," Journal of Allergy and Clinical Immunology, vol. 122, no. 2, pp. 261-266, 2008.
[8] R. Lande, J. Gregorio, V. Facchinetti, et al., "Plasmacytoid dendritic cells sense self-DNA coupled with antimicrobial peptide," Nature, vol. 449, no. 7162, pp. 564-569, 2007.

[9] J. Harder, U. Meyer-Hoffert, L. M. Teran, et al., "Mucoid Pseudomonas aeruginosa, TNF- $\alpha$, and IL- $\beta$, but not IL-6, induce human $\beta$-defensin-2 in respiratory epithelia," American Journal of Respiratory Cell and Molecular Biology, vol. 22, no. 6, pp. 714-721, 2000.

[10] A. Y. Liu, D. Destoumieux, A. V. Wong, et al., "Human $\beta$-defensin-2 production in keratinocytes is regulated by interleukin-1, bacteria, and the state of differentiation," Journal of Investigative Dermatology, vol. 118, no. 2, pp. 275-281, 2002.

[11] P. T. Liu, S. Stenger, H. Li, et al., "Toll-like receptor triggering of a vitamin D-mediated human antimicrobial response," Science, vol. 311, no. 5768, pp. 1770-1773, 2006.

[12] J. Harder, U. Meyer-Hoffert, K. Wehkamp, L. Schwichtenberg, and J.-M. Schröder, "Differential gene induction of human $\beta$ defensins (hBD-1, -2, -3, and -4) in keratinocytes is inhibited by retinoic acid," Journal of Investigative Dermatology, vol. 123, no. 3, pp. 522-529, 2004.

[13] S. Segaert and T. Simonart, "The epidermal vitamin D system and innate immunity: some more light shed on this unique photoendocrine system?" Dermatology, vol. 217, no. 1, pp. 7$11,2008$.

[14] G. Weber, J. D. Heilborn, C. I. C. Jimenez, A. Hammarsjö, H. Törmä, and M. Ståhle, "Vitamin D induces the antimicrobial protein hCAP18 in human skin," Journal of Investigative Dermatology, vol. 124, no. 5, pp. 1080-1082, 2005.

[15] T.-T. Wang, F. P. Nestel, V. Bourdeau, et al., "Cutting edge: 1,25-dihydroxyvitamin D3 is a direct inducer of antimicrobial peptide gene expression," Journal of Immunology, vol. 173, no. 5, pp. 2909-2912, 2004.

[16] D. Yang, O. Chertov, S. N. Bykovskaia, et al., " $\beta$-defensins: linking innate and adaptive immunity through dendritic and T cell CCR6," Science, vol. 286, no. 5439, pp. 525-528, 1999.

[17] J. Harder, U. Meyer-Hoffert, K. Wehkamp, L. Schwichtenberg, and J.-M. Schröder, "Differential gene induction of human $\beta$ defensins (hBD-1, -2, -3, and -4) in keratinocytes is inhibited by retinoic acid," Journal of Investigative Dermatology, vol. 123, no. 3, pp. 522-529, 2004.

[18] M. Murakami, B. Lopez-Garcia, M. Braff, R. A. Dorschner, and R. L. Gallo, "Postsecretory processing generates multiple cathelicidins for enhanced topical antimicrobial defense," Journal of Immunology, vol. 172, no. 5, pp. 3070-3077, 2004.

[19] H. Wu, G. Zhang, J. E. Minton, C. R. Ross, and F. Blecha, "Regulation of cathelicidin gene expression: induction by lipopolysaccharide, interleukin-6, retinoic acid, and Salmonella enterica serovar typhimurium infection," Infection and Immunity, vol. 68, no. 10, pp. 5552-5558, 2000. 
[20] J. Schauber, R. A. Dorschner, A. B. Coda, et al., "Injury enhances TLR2 function and antimicrobial peptide expression through a vitamin D-dependent mechanism," Journal of Clinical Investigation, vol. 117, no. 3, pp. 803-811, 2007.

[21] M. D. Howell, M. Boguniewicz, S. Pastore, et al., "Mechanism of HBD-3 deficiency in atopic dermatitis," Clinical Immunology, vol. 121, no. 3, pp. 332-338, 2006.

[22] S. P. Hong, M. J. Kim, M.-Y. Jung, et al., "Biopositive effects of low-dose UVB on epidermis: coordinate upregulation of antimicrobial peptides and permeability barrier reinforcement," Journal of Investigative Dermatology, vol. 128, no. 12, pp. 2880-2887, 2008.

[23] A. F. Gombart, N. Borregaard, and H. P. Koeffler, "Human cathelicidin antimicrobial peptide (CAMP) gene is a direct target of the vitamin D receptor and is strongly up-regulated in myeloid cells by 1,25-dihydroxyvitamin D3," FASEB Journal, vol. 19, no. 9, pp. 1067-1077, 2005.

[24] J. Schauber, Y. Oda, A. S. Büchau, et al., "Histone acetylation in keratinocytes enables control of the expression of cathelicidin and CD14 by 1,25-dihydroxyvitamin D3," Journal of Investigative Dermatology, vol. 128, no. 4, pp. 816-824, 2008.

[25] K. Yamasaki, A. Di Nardo, A. Bardan, et al., "Increased serine protease activity and cathelicidin promotes skin inflammation in rosacea," Nature Medicine, vol. 13, no. 8, pp. 975-980, 2007.

[26] E. J. Hollox, U. Huffmeier, P. L. J. M. Zeeuwen, et al., "Psoriasis is associated with increased $\beta$-defensin genomic copy number," Nature Genetics, vol. 40, no. 1, pp. 23-25, 2008.

[27] J. Schauber and R. L. Gallo, "Expanding the roles of antimicrobial peptides in skin: alarming and arming keratinocytes," Journal of Investigative Dermatology, vol. 127, no. 3, pp. 510512, 2007.

[28] R. Koczulla, G. von Degenfeld, C. Kupatt, et al., "An angiogenic role for the human peptide antibiotic LL-37/hCAP-18," Journal of Clinical Investigation, vol. 111, no. 11, pp. 16651672, 2003.

[29] M. Carretero, M. J. Escámez, M. García, et al., "In vitro and in vivo wound healing-promoting activities of human cathelicidin LL-37," Journal of Investigative Dermatology, vol. 128, no. 1, pp. 223-236, 2008.

[30] M. Lebwohl, A. Menter, J. Koo, and S. R. Feldman, "Combination therapy to treat moderate to severe psoriasis," Journal of the American Academy of Dermatology, vol. 50, no. 3, pp. 416430, 2004.

[31] M. Peric, S. Koglin, Y. Dombrowski, et al., "Vitamin D analogs differentially control antimicrobial peptide/"alarmin" expression in psoriasis," PLoS ONE, vol. 4, no. 7, article e6340, 2009. 


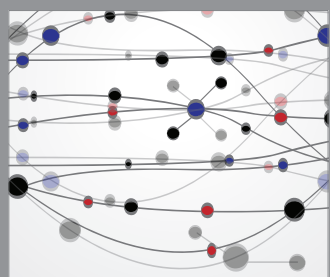

The Scientific World Journal
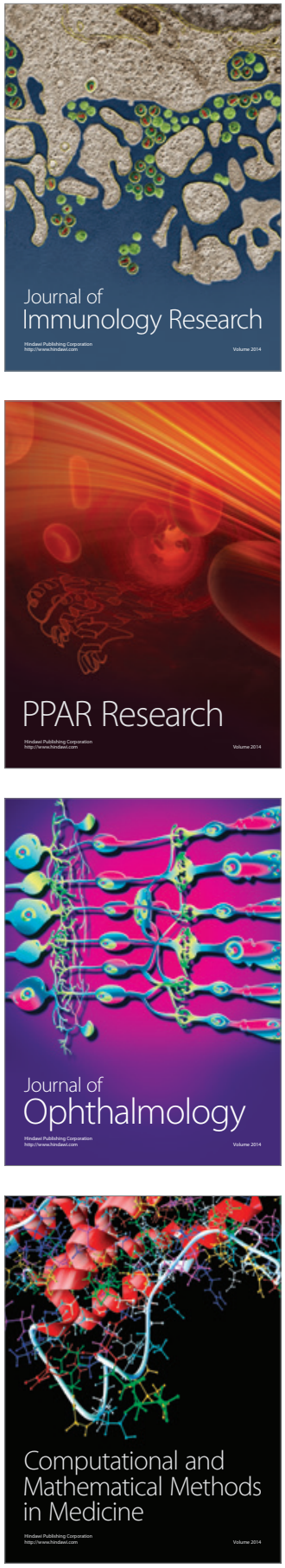

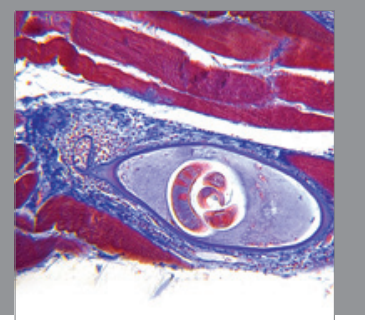

Gastroenterology

Research and Practice
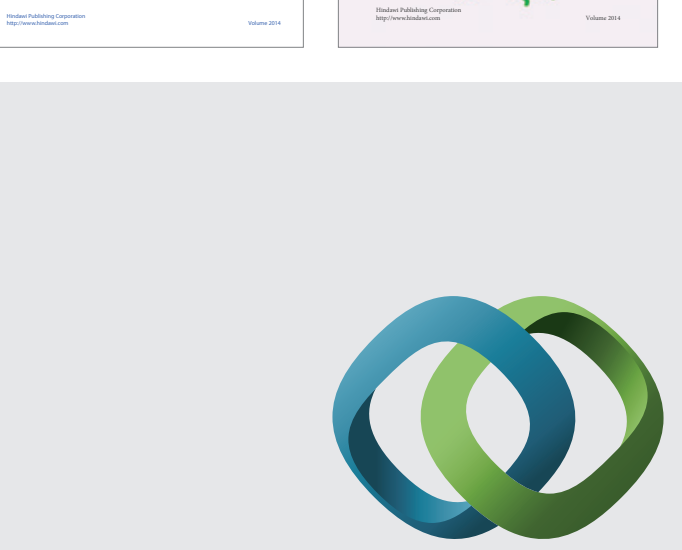

\section{Hindawi}

Submit your manuscripts at

http://www.hindawi.com
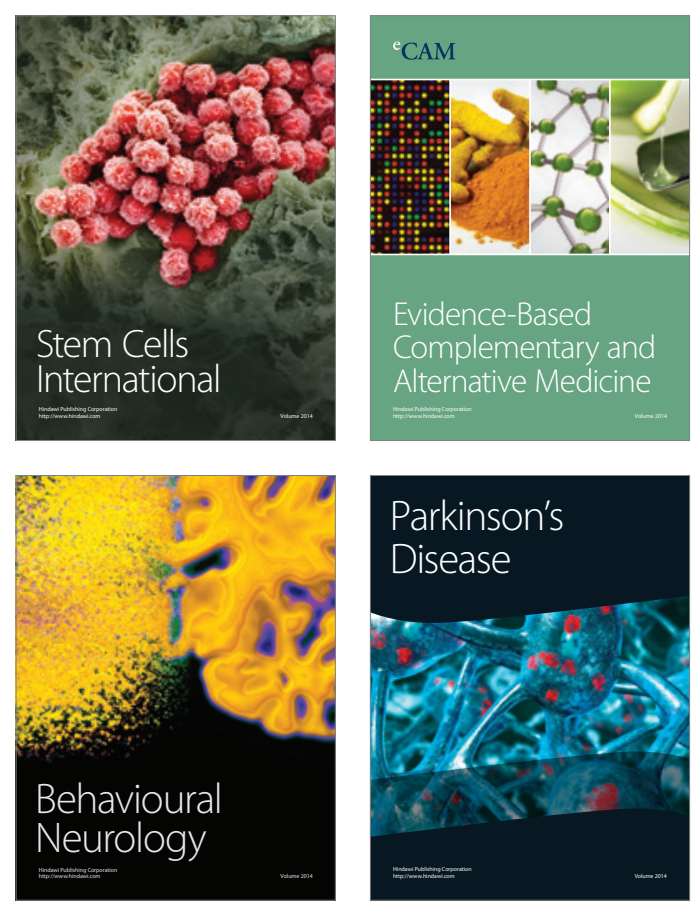

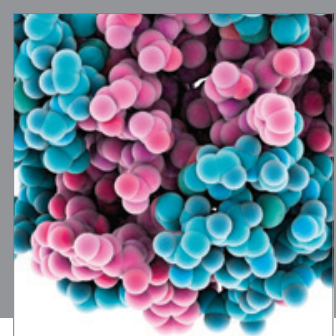

Journal of
Diabetes Research

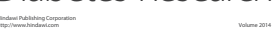

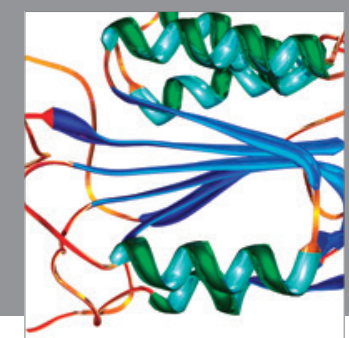

Disease Markers
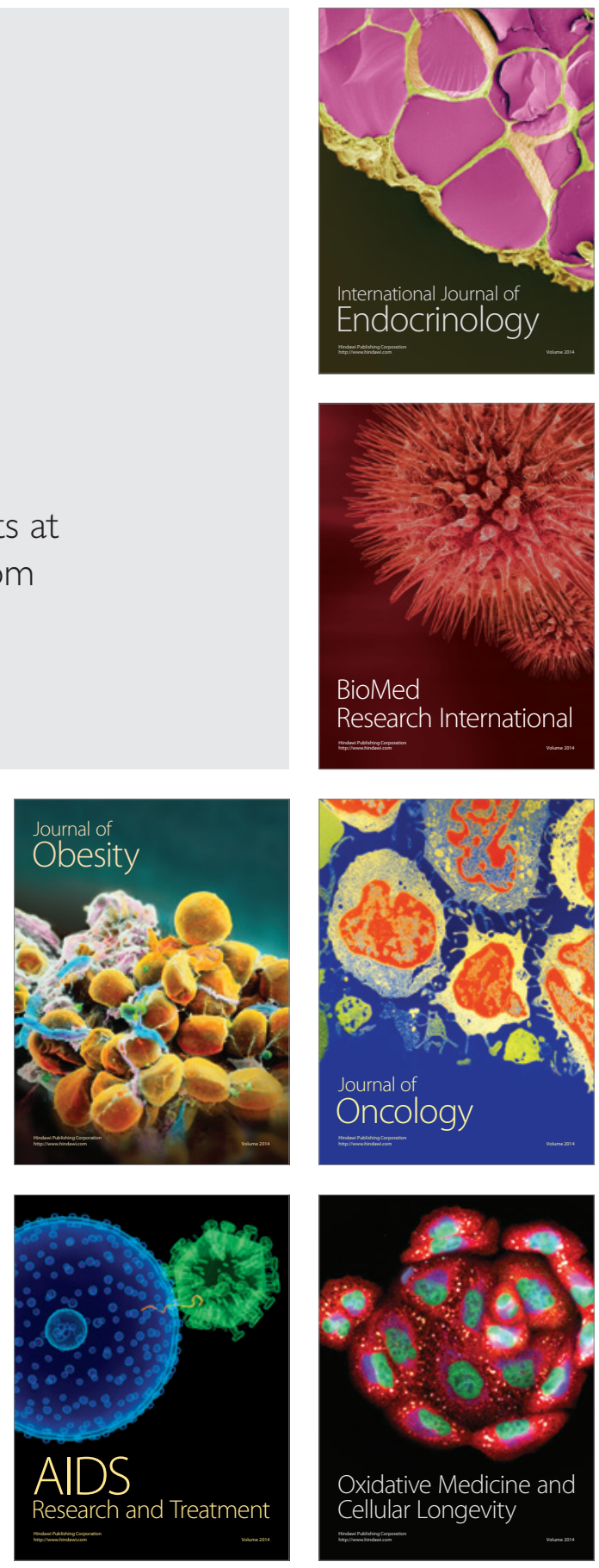